\title{
A CONSTRUÇÃO DE UM MODELO SOBRE A RETENÇÃO DE CLIENTES E SEUS ANTECEDENTES EM UM AMBIENTE DE SERVIÇOS
}

\author{
Gabriel Sperandio Milan \\ gsmilan@ucs.br \\ Universidade de Caxias do Sul - Caxias do Sul, RS / Brasil \\ Deonir De Toni \\ deonirdt@terra.com.br \\ Universidade de Caxias do Sul - Caxias do Sul, RS / Brasil
}

\begin{abstract}
Recebido em 11/07/2010
Aprovado em 16/05/2011

Disponibilizado em 01/08/2012

Avaliado pelo sistema double blind review

Revista Eletrônica de Administração

Editor: Luís Felipe Nascimento

ISSN 1413-2311 (versão on-line)

Editada pela Escola de Administração da Universidade Federal do Rio Grande do Sul.

Periodicidade: Quadrimestral
\end{abstract}

Sistema requerido: Adobe Acrobat Reader.

\section{RESUMO}

Este trabalho aborda a estratégia da retenção de clientes por meio da prática do marketing de relacionamento no ambiente de serviços. É proposto um Modelo Teórico, com suas respectivas hipóteses, no qual os construtos Satisfação de Clientes, Valor, Reputação do Provedor de Serviços e Confiança são considerados antecedentes da Retenção de Clientes. A análise central dos dados foi implementada por técnicas de estatística multivariada e pela Modelagem de Equações Estruturais. Os resultados indicam que o Modelo Teórico Reespecificado apresenta o melhor ajuste em relação Modelo Teórico inicial, embora precise de um maior amadurecimento teórico e empírico, até pelo ineditismo do modelo integrado. O trabalho propicia evidências relevantes, comprovando que o valor percebido pelos clientes é um construto antecedente da confiança depositada no provedor de serviços, relação esta mediada pela reputação do provedor de serviços; que a reputação do provedor de serviços é importante no contexto relacional em estudo; e que a retenção de clientes é positivamente influenciada pela confiança depositada no provedor de serviços.

Palavras-chave: Relacionamentos, Marketing de Relacionamento, Retenção de Clientes, Serviços, Modelagem de Equações Estruturais.

THE CONSTRUCTION OF A MODEL ABOUT CUSTOMER RETENTION AND ITS ANTECEDENTES IN AN ENVIRONMENT OF SERVICES 
This work approaches the strategy of customer retention by means of the practical of the relationship marketing in the environment of services. A Theoretical Model is proposed, with its respective hypothesis, in which the constructs Customer Satisfaction, Value, Reputation of the Services Provider and Trust are considered antecedents of Customer Retention. The central analysis of the data was implemented by techniques of multivariate statistics and the Structural Equations Modeling. The results indicate that the Respecificated Theoretical Model presents the best adjustment compared to initial Theoretical Model; even so it needs a theoretical and empirical evolution, despite of originality of the integrated model. The work propitiates relevant evidences, proving that the value perceived for the customers is one antecedent construct of the trust deposited in the services provider, and this relation is mediated by the reputation of the services provider; that the reputation of the services provider is important in the relational context in study; and that the customer retention is positively influenced by the trust deposited in the services provider.

Keywords: Relationships, Relationship Marketing, Customer Retention, Services, Structural Equation Modeling.

\section{INTRODUÇÃO}

O marketing de relacionamento vem sendo sugerido como uma área profícua para o desenvolvimento de estudos (GRÖNROOS, 1994), embora não deva ser visto como uma espécie de panacéia para todos os males empresariais (PILLAI; SHARMA, 2003; SHARMA; PILLAI, 2003; SHARMA, 2007). As empresas estão aprendendo que, ao invés da competição predatória, devem colaborar para competir (MORGAN; HUNT, 1994), emergindo oportunidades, tanto para compradores quanto para vendedores, de reduzir os riscos inerentes ao relacionamento, de aumentar os lucros e de obter uma possível vantagem competitiva sustentável no longo prazo (DONEY; CANNON, 1997; FONTENOT et al., 1998).

Com o crescente nível de competitividade no mercado, pode-se inferir que a retenção de clientes é um dos objetivos centrais do marketing de relacionamento, e o grande desafio passa a ser o de reconhecer os clientes, mostrando a eles o quanto a empresa os estima por terem lhe conferido sua preferência. Mas isso vai além da preocupação com a satisfação do cliente, que tem um papel essencial no desempenho das organizações (OLIVER, 2010), caracterizando-se como um novo modo de pensar a respeito do que gera receitas e lucro e sobre a forma de como se deveria fazer negócios (VAVRA; PRUDEN, 1995).

O lucro é importante, não somente como um fim em si mesmo, mas porque permite à empresa melhorar a geração de valor e propiciar incentivos para que os clientes, colaboradores e investidores permaneçam leais a ela (REICHHELD; MARKEY Jr.; HOPTON, 2000). Uma das principais tarefas dos gestores, então, não é apenas estabelecer 
relacionamentos com os clientes, mas também mantê-los, melhorando sua lucratividade e rentabilidade, mesmo que haja relativa dificuldade em se calcular os custos destes relacionamentos de forma específica (STORBACKA; STRANDVIK; GRÖNROOS, 1994).

Para manter ou ampliar seu market share, basicamente, as empresas dispõem de duas alternativas: a manutenção dos clientes atuais e a aquisição de novos clientes. As empresas que investem em relacionamentos não apenas atraem novos clientes, bem como mantêm e melhoram suas relações com os clientes atuais, inferindo-se que atrair novos clientes deveria ser visto como um objetivo intermediário (BERRY, 2002).

Com base nisso, Vavra e Pruden (1995) afirmam que a retenção de clientes vem se tornando imprescindível para o sucesso empresarial, o que vem sendo corroborado por diversos pesquisadores (REICHHELD; SASSER Jr., 1990; RUST; ZAHORIK, 1993; REICHHELD, 1993 e 1996; HESKETT et al., 1994; VAVRA, 1994; REICHHELD; MARKEY Jr.; HOPTON, 2000; MILAN, 2004 e 2006).

\section{MODELO TEÓRICO PROPOSTO E HIPÓTESES DE PESQUISA}

O objetivo do trabalho é apresentar os testes e a validação de um Modelo Teórico, que representa a prática relacional existente entre um provedor de serviços e seus clientes, resultando na retenção de clientes. Para tanto, são contemplados os seguintes construtos: satisfação de clientes, valor, reputação do provedor de serviços, confiança e retenção de clientes. Assim, é importante que se faça uma breve definição de cada um deles.

Cada vez mais a satisfação de clientes vem sendo reconhecida como uma medida do desempenho organizacional (ANDERSON, 1998) ou como um indicador de sucesso relativo aos esforços mercadológicos empreendidos por uma empresa (BABIN; GRIFFIN, 1998). O gerenciamento da satisfação de clientes se transformou em um imperativo para o sucesso de grande parte das empresas (ANDERSON; FORNELL; LEHMANN, 1994; ANDERSON; MITTAL, 2000; OLIVER, 2010).

Como a satisfação está fortemente arraigada às experiências dos clientes, ao abordar questões atinentes à qualidade em serviços, o julgamento de satisfação dos clientes se baseia tanto na experiência atual e em experiências passadas, reforçando o aspecto cumulativo da definição de satisfação proposto por uma significativa corrente de pesquisadores (JOHNSON; FORNELL, 1991; ANDERSON; FORNELL; LEHMANN, 1992; ANDERSON; FORNELL,

REAd I Porto Alegre - Edição 72 - N 2 - maio/agosto 2012 - p. 433-467 
1994; GARBARINO; JOHNSON, 1999), quanto em experiências futuras, as quais são antecipadas pelo julgamento do cliente (FORNELL, 1995).

Sob o enfoque cumulativo, Anderson, Fornell e Lehmann (1992) e Johnson e Fornell (1991) definem satisfação de clientes como uma avaliação global baseada em diversas experiências de compra e consumo ao longo do tempo. Anderson e Fornell (1994) também afirmam que a satisfação é uma avaliação contínua a respeito da habilidade de uma marca em proporcionar os benefícios que o cliente esteja buscando. Contudo, Oliver (1993) e Hallowell (1996) defendem que a satisfação está relacionada a uma transação ou a uma compra específica, tratando-a como um julgamento de avaliação, pós-compra, de uma ocasião determinada. Assim, se consolidam na literatura dois tipos de definição. Um que trata a satisfação de clientes como um processo cumulativo (TSE; WILTON, 1988; BLACKWELL; MINIARD; ENGEL, 2001), combinando aspectos perceptivos, avaliativos e psicológicos (OLIVER, 1980; BEARDEN; TEEL, 1983), e o outro, abordando-a como o resultado específico de uma experiência de consumo (HOWARD; SHETH, 1969; OLIVER, 1981).

Convergindo com esses dois enfoques da satisfação, Boulding et al. (1993), por sua vez, postulam que o construto da satisfação apresenta dois conceitos essenciais: a satisfação específica a uma transação e a satisfação cumulativa. Cabe ressaltar que a visão da satisfação específica a uma transação serve para a avaliação de situações específicas, enquanto a visão cumulativa é mais útil quando, por exemplo, o consumidor, ou o cliente, possui experiências passadas com determinado provedor de serviços.

A partir dessa discussão, Oliver (2010) definiu satisfação como sendo a resposta de plenitude do cliente. Ou seja, um julgamento que um produto ou um serviço tem como característica, devido ao fato de ter provido, ou estar provendo um nível agradável de plenitude relacionada ao consumo, podendo incluir níveis um pouco abaixo (desconfirmação negativa) ou que superam o nível esperado (desconfirmação positiva). Dessa forma, a satisfação pode ser definida como o grau no qual o cliente acredita que as suas expectativas serão supridas ou excedidas por meio dos benefícios recebidos (JURAN; GODFREY, 1999), ou, também, como o sentimento do consumidor no que se refere aos resultados provenientes do consumo em relação a um padrão de prazer ou desprazer (OLIVER, 1999a).

O valor percebido é o principal esteio que sustenta os relacionamentos existentes entre uma empresa e seus clientes, representando aquilo que o cliente entende como valioso para o início e para a manutenção de um relacionamento duradouro com um fornecedor específico no decorrer de sua vida útil de compra ou de consumo (RUST; ZEITHAML; LEMON, 2000).

REAd I Porto Alegre - Edição 72 - N 2 - maio/agosto 2012 - p. 433-467 
Traduz a relação entre os benefícios provenientes de uma determinada oferta versus os sacrifícios incorridos pelo cliente para a sua obtenção (ZEITHAML, 1988; JURAN; GODFREY, 1999; SIRDESHMUKH; SINGH; SABOL, 2002; AGUSTIN; SINGH, 2005).

Sendo assim, o valor percebido é uma avaliação global do cliente, que compara aquilo que recebe com o que lhe é dado em troca (ZEITHAML, 1988). Sob uma perspectiva relacional, o valor percebido pelo cliente está relacionado à avaliação comparativa entre os benefícios e os custos provenientes da manutenção do relacionamento com determinado provedor de serviços (SIRDESHMUKH; SINGH; SABOL, 2002). Em acréscimo, Juran e Godfrey (1999) definem valor como o custo relativo incorrido pelo cliente ao adquirir um nível de qualidade, proveniente de uma determinada oferta, que supra as suas expectativas, enquanto que Andreassen e Lindestad (1998) sugerem que o valor reflete a percepção de todos os atributos intrínsecos à qualidade como uma função do preço.

Ampliando o escopo do construto, Holbrook (1999) incorpora à sua definição aspectos tais como a interatividade, o relativismo, a afetividade e a própria experiência de compra ou de consumo. Dessa forma, o autor define valor como uma experiência de preferência relativa e interativa, que se refere à avaliação de um objeto (oferta, um produto e/ou um serviço) por parte de um indivíduo (cliente ou consumidor).

Como o conceito de valor é dinâmico, uma vez que a avaliação e a percepção do valor inerente a uma determinada oferta podem ser alteradas ao longo do tempo (WOODALL, 2003), sendo formado, direta e indiretamente, por elementos como expectativas, percepções, benefícios, sacrifícios, preço e qualidade (SINHA; DeSARBO, 1998), é possível considerá-lo um construto multidimensional. Por isso, Cronin Jr., Brady e Hult (2000) comentam que estudos sobre qualidade, satisfação e valor em ambientes de serviços são pertinentes. Isso se deve, em parte, porque o julgamento de valor pode ocorrer antes (valor esperado ou desejado) ou após a compra ou o consumo (valor percebido, avaliado ou julgado) (OLIVER, 1999b).

A reputação do provedor de serviços está relacionada à imagem da empresa, à forma com que o mercado percebe a organização, a sua marca e a sua oferta (STERN; ZINKHAN; JAJU, 2001), bem como à confiança depositada pelos clientes, à sua credibilidade e ao seu prestígio (GANESAN, 1994; WEBLEY, 2003; ALSOP, 2004). Está alicerçada na qualidade percebida e na sua confiabilidade (GARVIN, 1987) e arraigada ao comportamento passado da organização (SHMATIKOV; TALCOTT, 2005). Dessa forma, diversos pesquisadores 
defendem que a reputação é um construto antecedente à confiança (GANESAN, 1994; WEBLEY, 2003; SHMATIKOV; TALCOTT, 2005).

Muitas vezes, a incerteza sobre a escolha ou a manutenção de um provedor de serviços se deve às experiências de consumo passadas dos indivíduos e à influência exercida pela propaganda boca a boca, uma das formas de comunicação mais eficazes. Essas variáveis estão fortemente relacionadas à reputação do provedor de serviços junto ao mercado e ao sucesso do negócio (FITZSIMMONS; FITZSIMMONS, 2005). Outros aspectos relevantes e intrínsecos à reputação são: a prática da ética nos negócios, demonstrando integridade e sinceridade da empresa em suas ações; a alta visibilidade e a familiaridade da organização perante o mercado, ressaltando-se que somente a alta visibilidade não é o suficiente; e o prestígio percebido pelo mercado, o que pode resultar em uma performance superior, ou seja, em uma taxa de lucratividade mais elevada (WEBLEY, 2003; ALSOP, 2004; APÉRIA; BRONN; SCHULTZ, 2004; CARMELI, 2004).

No entanto, a reputação pode ser positiva ou negativa, sendo construída sobre um alicerce de confiabilidade, consistência comportamental e padrões éticos ao longo do tempo, credibilidade, admiração e respeito e prestígio (GANESAN, 1994; ALSOP, 2004). Fornecedores que apresentam uma reputação positiva, e que demonstram estar preocupados com o bem-estar da díade envolvida no relacionamento, principalmente no que se refere ao alcance dos objetivos das partes, tendem a ser mais confiáveis, denotando maior credibilidade (GANESAN, 1994; MAATHUIS; RODENBURG; SIKKEL, 2004).

$\mathrm{O}$ interesse pela confiança vem gerando um amplo corpo teórico sobre o tema, demonstrando sua relevância para aspectos atinentes à vida econômica (SMITH; CARROL; ASHFORD, 1995; NOOTEBOOM; BERGER; NOORDERHAVEN, 1997; ROUSSEAU et al., 1998; WICKS; BERMAN; JONES, 1999). A sua importância pode ser explicada pelo fato de ser vista como um fenômeno que contribui para o fortalecimento de relacionamentos interpessoais, intra-organizacionais e interorganizacionais (SVENSSON, 2001). Barney e Hansen (1994), inclusive, relacionam a confiança como uma fonte potencial de obtenção de vantagem competitiva, principalmente pelo fato desta variável apresentar um impacto positivo no que se refere à cooperação entre parceiros de troca (MAYER; DAVIS; SCHOORMAN, 1995), e por incrementar a habilidade das organizações em se adaptar à complexidade e às mudanças inerentes a mercados cada vez mais competitivos (McALLISTER, 1995).

O nível de confiança intrínseco a um relacionamento afeta o grau de defensividade entre os parceiros (ZAND, 1972). O clima defensivo estabelecido entre as partes pode afetar o 
nível de cooperação mútua, ou seja, quanto maior a defensividade existente, menor a profundidade na cooperação. Portanto, um comportamento confiável consiste em ações que aumentam a vulnerabilidade de uma parte em relação a outra, cujo comportamento não está sob controle, em uma situação na qual a penalidade que a parte vulnerável pode incorrer, caso a outra parte abuse desta vulnerabilidade, é maior que o benefício (utilidade) que poderá obter se esta mesma parte não abusasse de sua condição vulnerável (ZAND, 1972, seguindo os pressupostos de DEUTSCH, 1962).

Sendo assim, a confiança pode ser definida como a expectativa mantida por parte de uma pessoa ou organização de que a palavra ou a promessa feita por um parceiro de troca pode ser confiada (ROTTER, 1967). Confiar é tolerar os riscos inerentes ao nível de envolvimento e profundidade estabelecidos em um relacionamento entre parceiros de troca (SHEPPARD; SHERMAN, 1998). Sheppard e Sherman (1998) acreditam que a confiança não é um ato irracional, mas um ato de fé em pessoas, relacionamentos e organizações, e que pode ser gerenciado. Quando um parceiro percebe o comportamento da outra parte como sendo pouco confiável, hesitará em revelar ou trocar informações, rejeitará sua influência e se esquivará de seu controle relacional. Por outro lado, quando a confiança entre as partes aumenta, se eleva, igualmente, o desejo e a disposição de influenciarem-se um ao outro, reforçando a receptividade mútua destas influências (ZAND, 1972).

Para Rousseau et al. (1998) e Hawes, Mast e Swan (1989), a confiança ajuda a reduzir a incerteza e o risco específicos de uma transação, e pode ser identificada em termos da percepção de um cliente quanto à confiabilidade, honestidade, integridade e padrões éticos elevados representativos de uma organização de serviços (COULTER; COULTER, 2002). Portanto, no setor de serviços, a confiança é particularmente significativa uma vez que os clientes, em essência, não compram o serviço em si, mas sim uma promessa implícita ou explícita de serviço, a qual poderá se configurar, ou não, no futuro (CLAYCOMB; MARTIN, 2001; BITNER, 1995).

Finalmente, a retenção de clientes, que está relacionada à manutenção da preferência do cliente por um determinado fornecedor, resultando, em última instância, na intenção e na efetiva repetição de negócios, com tal fornecedor, ao longo do tempo (FORNELL; RYAN; WESTBROOK, 1990; REICHHELD; SASSER Jr., 1990; VAVRA, 1994; HAWKINS; BEST; CONEY, 1995; VAVRA; PRUDEN, 1995; REICHHELD, 1996; RUST; ZEITHAML; LEMON, 2000; OLIVER, 2010). Vavra e Pruden (1995) afirmam que a retenção de clientes é 
a chave para o sucesso no mercado do novo milênio, a qual é proposta como o componente mais importante para a consolidação da participação de mercado da empresa, sendo direcionada, basicamente, pela satisfação do cliente (RUST; ZAHORIK, 1993). Alguns estudos indicam uma forte relação entre a satisfação e a retenção de clientes. Tais estudos têm descoberto que incrementos no nível de satisfação geral resultam no aumento das intenções de repetição de compra (ANDERSON, 1994; ZEITHAML; BERRY; PARASURAMAN, 1996), impactando, positivamente, no comportamento de recompra (BOLTON, 1998).

Como as empresas investem recursos a fim de atrair clientes (custos de aquisição) para, então, cultivá-los (custos de manutenção) (ANDERSON; MITTAL, 2000), a retenção de clientes pode diminuir os custos de comercialização atinentes à prospecção de clientes, os custos com ações de comunicação relacionadas à atração de clientes e os custos incorridos para familiarizar os novos clientes com as práticas da empresa (MITTAL; LASSAR, 1998).

O custo de retenção de um cliente atual é menor que o custo de atração de um novo cliente (BOLTON, 1998). Os custos de aquisição podem chegar até cinco vezes mais em relação aos custos de manutenção (KOTLER, 2000). É importante salientar que uma taxa de retenção de clientes mais elevada pode significar uma base de clientes que compra mais freqüentemente e em volumes mais expressivos, bem como uma redução nos custos de transação (FORNELL; WERNERFELT, 1987; REICHHELD; SASSER Jr., 1990; ANDERSON; MITTAL, 2000). Desse modo, as ações direcionadas à retenção de clientes devem almejar a maximização da probabilidade do cliente retornar para compras futuras, a maximização do volume dessas compras no longo prazo e a minimização da probabilidade do cliente comprar de um outro fornecedor (RUST; ZEITHAML; LEMON, 2000).

Para facilitar o entendimento das relações causais estabelecidas, e como síntese das hipóteses de pesquisa, a Figura 1 apresenta o Modelo Teórico proposto.

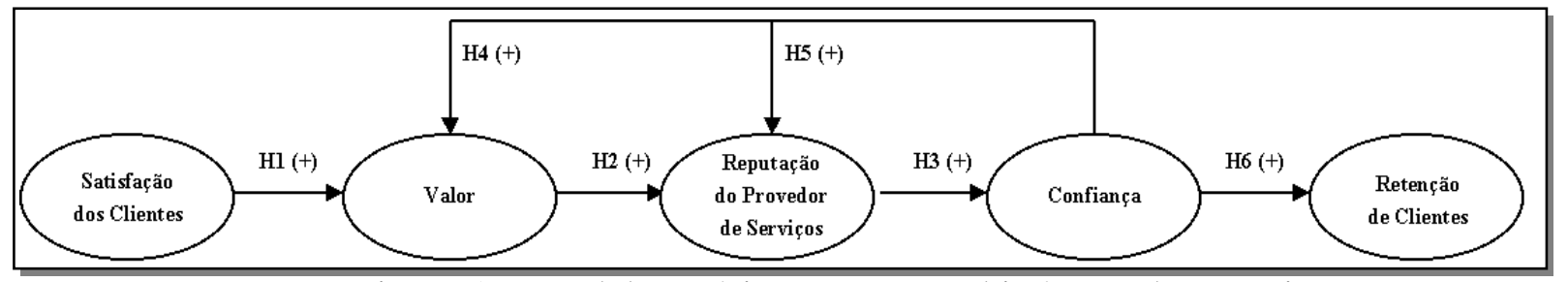

Figura 1 - Modelo Teórico proposto e hipóteses de pesquisa

Fonte: autores

Para tanto, as hipóteses propostas (Hi) são as seguintes:

REAd I Porto Alegre - Edição 72 - N 2 - maio/agosto 2012 - p. 433-467 
- H1: O valor percebido pelos clientes é positivamente influenciado pela satisfação dos clientes;

- H2: A reputação do provedor de serviços é positivamente influenciada pelo valor percebido pelos clientes;

- H3: A confiança no provedor de serviços é positivamente influenciada pela reputação do provedor de serviços;

- H4: O valor percebido pelos clientes é positivamente influenciado pela confiança no provedor de serviços;

- H5: A reputação do provedor de serviços é positivamente influenciada pela confiança no provedor de serviços; e

- H6: A retenção de clientes é positivamente influenciada pela confiança no provedor de serviços.

\section{MÉTODO DE PESQUISA EMPREGADO}

Este trabalho se caracteriza como uma pesquisa descritiva, de natureza quantitativa. Ao investigar as relações existentes entre os construtos em análise, mediante a proposição de hipóteses de pesquisa, foi realizado um estudo de corte transversal único com a aplicação de uma survey (CHURCHILL Jr., 1995; HAIR Jr.; BUSH; ORTINAU, 2000; MALHOTRA, 2006). Para avaliar as relações propostas, foi empregada a Modelagem de Equações Estruturais (KLINE, 2005; HAIR Jr. et al., 1998; ARBUCKLE, 2009), por meio de uma modelagem de desenvolvimento incremental de modelos (JÖRESKOG; SÖRBOM, 1993 apud MacCALLUM, 1995; HAIR Jr. et al., 1998), pois apesar de propor um modelo inicial, tem-se o objetivo de melhorá-lo a partir da modificação dos modelos estrutural e de mensuração (HAIR Jr. et al., 1998), resultando em um modelo causal mais adequado.

\section{Ambiência da Pesquisa}

A pesquisa foi desenvolvido junto a um Grupo multinacional, que atua no mercado brasileiro desde o final da década de 70. O Grupo Empresarial opera em três segmentos de mercado: alimentação e restaurantes, hotelaria e viagens e produtividade e marketing, contando com 28 marcas em seu portfólio. No Brasil, são 30.000 colaboradores, atendendo a 60.000 empresas-clientes. O seu faturamento, em 2009, resultou em cerca de R \$ 8,5 bilhões.

REAd I Porto Alegre - Edição 72 - N 2 - maio/agosto 2012 - p. 433-467 
No entanto, a população considerada para esta pesquisa compreendeu apenas os clientes de uma de suas Unidades de Negócio, focada no segmento alimentação e restaurantes, no Estado do Rio Grande do Sul, localizados, mais especificamente, na Grande Porto Alegre e na região Nordeste do Estado, devido à representatividade em sua carteira de clientes, tanto em relação ao número de clientes nestas duas regiões quanto ao volume de negócios gerado. Por entender que tais informações têm caráter estratégico, a empresa preferiu não divulgar o número total de clientes no Estado, o volume de negócios e informações complementares.

A partir dessa delimitação inicial, foi definida a amostra para a pesquisa, utilizando-se a técnica de amostragem não-probabilística por conveniência (HAIR Jr.; BUSH; ORTINAU, 2000; MALHOTRA, 2006). Levando em conta a utilização da Modelagem de Equações Estruturais e a complexidade dos modelos, Kline (2005) defende que a amostra deveria contemplar 200 casos ou mais, enquanto Hu e Bentler (1995) sugerem que, para proporcionar índices aceitáveis de ajustamento dos modelos, é recomendável que a amostra totalizasse 250 casos ou mais. Por isso, optou-se pela definição de uma amostra de, pelo menos, 250 casos.

\section{Operacionalização dos Construtos e Elaboração do Instrumento de Coleta de Dados}

Para a elaboração do instrumento de coleta de dados, foram operacionalizadas as variáveis intrínsecas aos construtos, definindo-se escalas, estrutura e ordem das questões e formatação (HAIR Jr.; BUSH; ORTINAU, 2000; MALHOTRA, 2006). Conforme apresentado no Modelo Teórico (Figura 1), cinco construtos integram a pesquisa. Tais construtos são variáveis não observáveis, variáveis que não podem ser observadas diretamente (variáveis latentes), mas que podem ser representadas e aferidas por meio de uma ou mais variáveis, ou indicadores, que se constituem em variáveis observáveis (BOLLEN, 1989; HAIR Jr. et al., 1998; ARBUCKLE, 2009; BYRNE, 2009).

Em relação ao construto Satisfação de Clientes, foi utilizada uma escala com seis itens. Esta escala foi adaptada de Cannon e Perreault Jr. (1999) (SATISF_1 e 3 a 5) e de Hennig-Thurau, Gwinner e Gremler (2002) (SATISF_6). O item de escala SATISF_2 foi adaptado de ambos os estudos. As variáveis SATISF_3 e 4 são itens de escala com escore reverso. Para o construto Valor, adotou-se uma escala com quatro itens, sendo que a mesma foi adaptada de Perin et al. (2004) (VALOR_1 a 4), que utilizaram como base o estudo desenvolvido por Sirdeshmukh, Singh e Sabol (2002).

REAd I Porto Alegre - Edição 72 - N 2 - maio/agosto 2012 - p. 433-467 
Quanto ao construto Reputação do Provedor de Serviços, a escala apresenta cinco itens, e foi adaptada de Ganesan (1994) (REPUT_1 a 3 e 5) e de Doney e Cannon (1997) (REPUT_1 a 3), enquanto o item de escala REPUT 4 foi adicionado pelos autores. A variável REPUT_3 trata-se de um item de escala com escore reverso. Para o construto Confiança, a escala possui nove itens e foi adaptada de Doney e Cannon (1997) (CONF_1 a 7 e 9), também utilizada por Hewett, Money e Sharma (2002), e de Morgan e Hunt (1994) (CONF_8). As variáveis CONF_2 e 9 são itens de escala com escore reverso. E, por fim, para o construto Retenção de Clientes, a escala é composta por seis itens, e foi adaptada de Ganesh, Arnold e Reynolds (2000). As variáveis REPUT_2 e 5 são itens de escala com escore reverso.

As escalas, ou melhor, os itens de escala utilizados, e que foram desenvolvidos ou testados originalmente em língua inglesa, exceto as escalas utilizadas por Santos (2001) e Perin et al. (2004), já traduzidas para a língua portuguesa, foram submetidas ao processo de tradução reversa (back translation), sugerida por Dillon, Madden e Firtle (1994). Para o construto Valor, e seus respectivos itens de escala, foi empregada uma escala de diferencial semântico de 10 pontos e, para os demais construtos, uma escala do tipo Likert de sete pontos, indicando em seus extremos de "1.discordo totalmente" a "7.concordo totalmente".

\section{Validação do Instrumento de Coleta de Dados e o Processo de Coleta de Dados}

Após a estruturação do instrumento de coleta de dados, procedeu-se à validade de conteúdo, validade de face (KINNEAR; TAYLOR, 1996; HAIR Jr.; BUSH; ORTINAU, 2000) ou validade nominal, que consiste de uma avaliação subjetiva, porém, sistemática, da representatividade do conteúdo de uma ou mais escalas utilizadas para a mensuração dos construtos em estudo (MALHOTRA, 2006). A validade de conteúdo serve para se verificar quão bem os componentes mensuráveis do construto, ou seja, as variáveis observáveis, representam o construto em análise (HAIR Jr.; BUSH; ORTINAU, 2000), capturando os principais aspectos que o definem (DILLON; MADDEN; FIRTLE, 1994).

Para tanto, o instrumento de coleta de dados foi submetido a três experts da área. Para a finalização do questionário, foi realizado pré-teste, aplicando a trinta respondentes. Embora os respondentes não tenham tido dúvidas muito expressivas, procedeu-se a algumas melhorias de ordem e de linguagem para a versão final do questionário. Como foram implementadas

REAd I Porto Alegre - Edição 72 - N 2 - maio/agosto 2012 - p. 433-467 
alterações, além da forma de aplicação do questionário no pré-teste, que contou com a presença e orientação de um pesquisador aos respondentes, tais casos foram descartados.

\section{Coleta de Dados, Exame dos Dados e Amostra Final}

O processo de coleta de dados foi realizado pelo método de levantamento, com base na aplicação do questionário de pesquisa, mediante auto-preenchimento dos respondentes. Ao todo, foram distribuídos 898 questionários, obtendo-se, ao final do processo de coleta de dados, 278 questionários, ou seja, um retorno de cerca de $31 \%$.

No sentido de se obter uma amostra de melhor qualidade, dois tipos de análise foram implementadas. Na primeira análise, foi verificada a existência de dados omissos e de outliers. Como não foi observado um padrão para as não respostas, optou-se por incluir na amostra somente casos com dados completos, procedimento conhecido como abordagem de caso completo (HAIR Jr. et al., 1998; KLINE, 2005), empregando-se o método listwise deletion, que é o método mais popular ao se lidar com casos omissos (BYRNE, 2009). Dos 278 questionários respondidos, 4 foram eliminados. Quanto aos outliers, com base no teste de padronização das variáveis, calculando-se os z-scores, e em sua análise (HAIR Jr. et al., 1998; KLINE, 2005), foram identificados 5 casos, também eliminados. Na segunda análise, partiuse para a análise da normalidade, multicolinearidade, linearidade e homoscedasticidade.

Salvo na análise da multicolinearidade, que mostrou haver pares de variáveis altamente intercorrelacionadas, os resultados foram satisfatórios. A multicolinearidade ocorre quando as intercorrelações entre variáveis são relativamente altas a ponto de inviabilizar algumas operações matemáticas ou por apresentarem instabilidade nos resultados, o que poderia ser provocado por denominadores muito próximos a zero. Ao analisar as intercorrelações, variáveis com valores acima de 0,85 podem ser consideradas redundantes (KLINE, 2005). Dessa forma, com base na análise de multicolinearidade dos dados, foi verificada a existência de variáveis redundantes, o que suscitou uma depuração nas escalas.

\section{Depuração das Escalas Utilizadas}

Ao identificar a existência de multicolinearidade dos dados, optou-se pela depuração das escalas utilizadas, eliminando algumas variáveis. A eliminação das variáveis se baseou na 
magnitude das intercorrelações e em simulações do ajuste dos submodelos (construtos) que poderiam ter variáveis eliminadas em suas escalas.

Para o construto Satisfação de Clientes foram eliminadas as variáveis SATISF_2 e SATISF_6. Cabe comentar que, inicialmente, eliminou-se a variável SATISF_1 ao invés da variável SATISF_2. No entanto, o resultado proveniente de simulações indicou que seria mais adequada a eliminação da variável SATISF_2.

Embora o critério de análise indicasse a possibilidade de eliminação de uma das variáveis do construto Valor, VALOR_3 ou VALOR_4, dois aspectos explicam a manutenção de ambas. Em primeiro lugar, pela magnitude da correlação entre as variáveis $(0,866)$, levemente acima do aceitável e, em segundo lugar, que, ao retirar uma destas variáveis, em ambos os casos, o submodelo não obteve bons resultados em sua operacionalização. Seguindo os mesmos critérios, para o construto Confiança, foram eliminadas as variáveis CONF_5 e CONF_8. Em relação aos demais construtos, suas escalas permaneceram inalteradas.

\section{Especificação do Modelo e o Modelo Híbrido Testado}

A especificação é a forma de se exprimir formalmente um modelo (HOYLE, 1995), representando um padrão linear de relacionamentos (relações causais) entre um conjunto de variáveis (MacCALLUM, 1995), que é compreendido tanto pelas variáveis latentes (construtos) quanto pelas variáveis observáveis (HOYLE, 1995). Com base no Modelo Teórico proposto, deve-se iniciar a especificação do modelo (HAIR et al., 1998), resultando nas equações estruturais que irão representar o seu Diagrama de Caminhos, o modelo estrutural e o modelo de mensuração. Portanto, inicialmente, foram estabelecidas formalmente as relações causais propostas e, como decorrência disso, definidas as respectivas equações estruturais que caracterizam o modelo estrutural e o modelo de mensuração:

$$
\begin{aligned}
& \text { VALOR }=\text { b0 + b1 SATISF + b2 CONF + e1 } \\
& \text { REPUT }=\text { b3 + b4 VALOR + b5 CONF + e2 } \\
& \text { CONF }=\text { b6 + b7 REPUT + e3 } \\
& \text { RETEN }=\text { b8 + b9 CONF + e4 }
\end{aligned}
$$

O modelo estrutural representa as inter-relações de dependência entre as variáveis latentes (construtos) (HAIR Jr. et al., 1998), enquanto o modelo de mensuração especifica o REAd I Porto Alegre - Edição 72 - N 2 - maio/agosto 2012 - p. 433-467 
relacionamento de cada variável observável (KLINE, 2005), identificando quais indicadores pertencem a cada um dos construtos que integram o modelo (HAIR Jr. et al., 1998). Os modelos estrutural e de mensuração, quando combinados, resultam em um modelo estatístico abrangente, o modelo híbrido, utilizado para avaliar as relações entre variáveis que estão livres de erros de mensuração (HOYLE, 1995). Pela facilidade gráfica de alguns softwares estatísticos, os modelos estrutural e de mensuração podem ser representados simultaneamente por um modelo híbrido, denotando as relações causais entre os construtos e os relacionamentos existentes entre os indicadores e o construto a que pertencem (PERIN, 2001; ARBUCKLE, 2009; BYRNE, 2009).

Outro aspecto importante é a definição sobre a direção da causalidade entre variáveis latentes (construtos) e as variáveis observáveis (indicadores), decidindo qual o tipo de construto utilizado no estudo, se refletivos ou formativos (BOLLEN, 1989). A escolha entre a especificação de construtos refletivos ou formativos deve estar fundamentada em aspectos teóricos, considerando as direções causais entre as variáveis latentes (construtos) e as variáveis observáveis (indicadores) (DIAMANTOPOULOS; WINKLHOFER, 2001; WILCOX; HOWELL; BREIVIK, 2008).

"Estabelecer a prioridade causal é necessário para determinar se um indicador é uma causa [variáveis formativas] ou um efeito [variáveis refletivas] de uma variável latente" (BOLLEN, 1989, p. 65). As variáveis refletivas são intercambiáveis, ou seja, a eliminação de uma variável não muda a essência da natureza do construto. No caso de variáveis formativas, a eliminação de uma delas pode omitir parte do construto, alterando a sua natureza (DIAMANTOPOULOS; WINKLHOFER, 2001; WILCOX; HOWELL; BREIVIK, 2008).

Neste horizonte, foi definido que o modelo e seus construtos são refletivos. Para que um modelo seja considerado refletivo, algumas características são fundamentais: (i) a direção da causalidade deve ser da variável latente para a variável observável; (ii) as variáveis observáveis devem ter consistência interna e serem correlacionadas; e (iii) a inclusão ou eliminação de alguma variável não deve alterar o significado do construto (JARVIS; MACKENZIE; PODSAKOFF, 2003). 
Além dos construtos inseridos no modelo contemplarem as referidas características, foi considerado, também, o fato de que as estruturas de cálculo dos softwares que operacionalizam a Modelagem de Equações Estruturais têm adotado a dimensão refletiva quase como uma aceitação automática (default) (DIAMANTOPOULOS; WINKLHOFER, 2001). Para Kline (2005), tal escolha, na mensuração de modelos, pode ser vista como usual. Como decorrência de tais decisões, o modelo híbrido utilizado no trabalho é apresentado na Figura 2. Além das variáveis latentes (construtos) e das variáveis observáveis (indicadores), foram inseridos os erros de mensuração intrínsecos a cada um dos construtos.

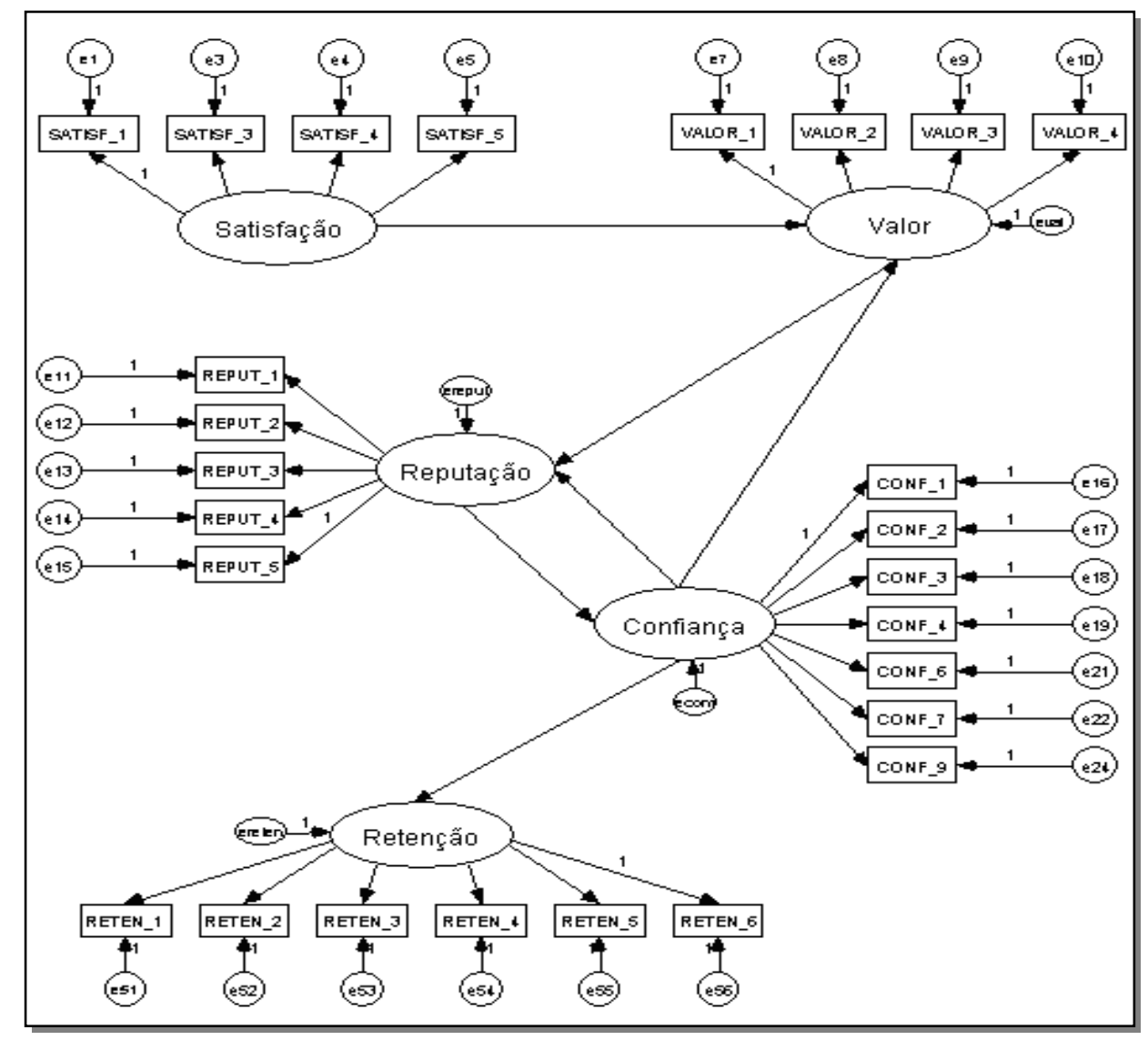

Figura 2 - Modelo híbrido testado

Fonte: autores

\section{Matriz de Entrada de Dados e Método de Estimação}

No que se refere à definição da matriz de entrada de dados, foi escolhida a matriz de covariância. Mesmo que haja a alternativa de se utilizar a matriz de correlações, a estimação de parâmetros em Modelagem de Equações Estruturais deveria sempre se basear na matriz de covariâncias (CUDECK, 1989). A vantagem da matriz de covariância em relação à matriz de 
correlação é que ela propicia mais informação do que simplesmente dados padronizados (BREI; LIBERALI, 2004), fornecendo comparações válidas entre diferentes populações ou amostras, o que não é possível quando o modelo é estimado com a matriz de correlação (HAIR Jr. et al., 1998). Isto também é recomendado por Hulland, Chow e Lam (1996), Kline (2005) e Byrne (2009). Portanto, para a entrada de dados, optou-se pela matriz de covariância.

Em relação ao método de estimação de parâmetros, optou-se pelo método da Máxima Verossimilhança (ML - Maximum Likelihood), que é um método que, por meio de iterações, melhora as estimativas de parâmetros para minimizar uma função de ajuste especificada (HAIR Jr. et al., 1998), e que apresenta uma performance relativamente boa sob uma variedade de condições analíticas nem sempre ideais (HOYLE; PANTER, 1995; BYRNE, 2009).

\section{ANÁLISE E DISCUSSÃO DOS RESULTADOS}

\section{Amostra Final e Caracterização dos Respondentes}

A amostra final resultou em 269 casos válidos. As principais características dos respondentes são apresentadas na Tabela 1 .

Tabela 1 - Perfil dos respondentes

\begin{tabular}{|c|c|c|c|c|c|c|c|}
\hline \multicolumn{2}{|c|}{ Sexo } & \multicolumn{2}{|c|}{ Tipo de Empresa } & \multicolumn{2}{|c|}{ Porte (Critérios da Empresa) } & \multicolumn{2}{|c|}{ Localização das Empresas } \\
\hline $\mathbf{F}$ & $\mathbf{M}$ & & & & & \multirow[b]{2}{*}{ Grande Porto Alegre } & \multirow{2}{*}{126} \\
\hline \multirow{3}{*}{100} & \multirow{3}{*}{169} & Públicas & 20 & 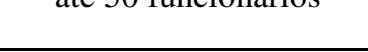 & 110 & & \\
\hline & & \multirow{2}{*}{ Privadas } & \multirow{2}{*}{249} & 51 a 150 funcionários & 77 & \multirow{2}{*}{ Região Nordeste } & \multirow{2}{*}{143} \\
\hline & & & & mais de 151 funcionários & 77 & & \\
\hline
\end{tabular}

Fonte: autores

\section{Validação Individual dos Construtos}

Para validar o modelo integrado, com seus respectivos construtos, é fundamental que, antes disso, se proceda à validação individual dos construtos ou submodelos (ANDERSON; GERBING, 1988; HAIR Jr. et al., 1998; GARVER; MENTZER, 1999; KLINE, 2005). Para a 
validação individual dos construtos foram avaliadas a unidimensionalidade, a confiabilidade, e as validades convergente e discriminante dos mesmos.

Para aferição e análise da unidimensionalidade, procedeu-se a uma Análise Fatorial Exploratória (AFE) pelo método de componentes principais com rotação ortogonal Varimax para cada construto, minimizando o número de variáveis com cargas altas sobre um fator (MALHOTRA, 2006), por meio da maximização do quadrado das variâncias das cargas dos fatores (JOHNSON; WICHERN, 1992), evidenciando que a matriz de correlações é adequada à técnica de análise escolhida e que todos os construtos são formados por um único fator.

Como o Alfa de Cronbach presume que os itens de escala são unidimensionais e que todos estes itens são igualmente correlacionados (GERBING; ANDERSON, 1988), tendendo a ser uma medida "inflada" pela forma como trata as variâncias dos erros associadas aos indicadores (FINN, 2000), optou-se, também, pela confiabilidade composta, e pela variância extraída. As medidas foram calculadas para cada construto a partir das cargas padronizadas e dos erros de mensuração das variáveis. Como critério para a confiabilidade composta, valores iguais ou superiores a 0,70 são aceitáveis. Para a variância extraída, os valores deveriam exceder 0,50 (HAIR Jr. et al., 1998; GARVER; MENTZER, 1999).

Os valores relativos ao Alfa de Cronbach variaram de 0,88 a 0,94 , acima do valor recomendado, que é de 0,70 (CHURCHILL Jr., 1979; NUNNALLY; BERNSTEIN, 1994; HAIR Jr. et al., 1998). A confiabilidade composta de todos os construtos ficou acima do valor recomendado, variando de 0,92 a 0,95. Para a variância extraída, os valores obtidos também foram satisfatórios, variando de 0,66 a 0,82. Os resultados, portanto, conferem confiabilidade às escalas utilizadas para a mensuração dos construtos inseridos no trabalho (Tabela 2).

Tabela 2 - Alfa de Cronbach, confiabilidade composta e variância extraída por construto

\begin{tabular}{c|c|c|c}
\hline Construtos & Alfa de Cronbach & Confiabilidade Composta & Variância Extraída \\
\hline SATISF & 0,92 & 0,94 & 0,81 \\
\hline VALOR & 0,91 & 0,95 & 0,82 \\
\hline REPUT & 0,88 & 0,93 & 0,72 \\
\hline CONF & 0,94 & 0,92 & 0,79 \\
\hline RETEN & 0,88 & 0,92 & 0,66 \\
\hline
\end{tabular}

Fonte: autores

A validade convergente dos construtos foi analisada de duas formas: (i) pela análise da significância estatística dos parâmetros estimados (cargas fatoriais das variáveis), pelos $t$-values dos indicadores relativos a cada construto, que devem ser iguais ou maiores do que 
1,96, lhes conferindo significância estatística (p<0,05) (DUNN; SEAKER; WALLER, 1994; GARVER; MENTZER, 1999); e (ii) pela avaliação das medidas de ajuste a partir a Análise Fatorial Confirmatória (AFC) implementada para cada construto (BAGOZZI; YI; PHILLIPS, 1991; MARSH; GRAYSSON, 1995; KLINE, 2005). Tanto pela análise dos t-values, que demonstram que todos os parâmetros estimados são estatisticamente significantes, quanto pelas medidas de ajuste dos construtos, observa-se que há validade convergente (Tabela 3).

Tabela 3 - Medidas de ajuste por construto (submodelo)

\begin{tabular}{c|c|c|c|c|c|c}
\hline Construtos & GFI & AGFI & RMSEA & TLI & NFI & CFI \\
\hline SATISF & 0,990 & 0,948 & 0,083 & 0,987 & 0,993 & 0,996 \\
\hline VALOR & 0,987 & 0,866 & 0,154 & 0,958 & 0,992 & 0,993 \\
\hline REPUT & 0,985 & 0,942 & 0,076 & 0,981 & 0,987 & 0,992 \\
\hline CONF & 0,983 & 0,952 & 0,049 & 0,992 & 0,991 & 0,996 \\
\hline RETEN & 0,981 & 0,935 & 0,075 & 0,979 & 0,986 & 0,991 \\
\hline
\end{tabular}

Nota: Para o GFI, AGFI, TLI, NFI e CFI, valores acima de 0,90 indicam um bom ajuste do modelo aos dados, e para o RMSEA, valores entre 0,05 e 0,08 são tidos como aceitáveis (HAIR Jr. et al., 1998; KLINE, 2005).

Fonte: autores

Para a identificação de validade discriminante entre os construtos, foi utilizado o procedimento sugerido por Fornell e Larcker (1981). Por meio deste procedimento, as variâncias extraídas dos construtos são comparadas às variâncias compartilhadas, que são calculadas pelas correlações entre construtos ao quadrado. Conseqüentemente, há validade discriminante entre os construtos quando os mesmos apresentarem variâncias extraídas maiores que as variâncias compartilhadas com os demais construtos.

Como a variância extraída do construto REPUT $(0,72)$ ficou levemente inferior à variância compartilhada com o construto CONF (0,76), pode-se dizer que estes dois construtos estão ligeiramente correlacionados, o que pode suscitar a inferência em torno da redundância entre estas duas dimensões. Entretanto, mesmo considerando tal reflexão, verifica-se que, de forma geral, há validade discriminante entre os construtos. Para tanto, a Tabela 4 é elucidativa.

Tabela 4 - Variâncias extraídas e variâncias compartilhadas

\begin{tabular}{c|c|c|c|c|c}
\hline Construtos & SATISF & VALOR & REPUT & CONF & RETEN \\
\hline SATISF & $\mathbf{0 , 8 1}$ & & & & \\
\hline VALOR & 0,76 & $\mathbf{0 , 8 2}$ & & & \\
\hline REPUT & 0,64 & 0,61 & $\mathbf{0 , 7 2}$ & & \\
\hline CONF & 0,59 & 0,54 & 0,76 & $\mathbf{0 , 7 9}$ & \\
\hline RETEN & 0,58 & 0,59 & 0,58 & 0,59 & $\mathbf{0 , 6 6}$ \\
\hline
\end{tabular}

REAd I Porto Alegre - Edição 72 - N² 2 maio/agosto 2012 - p. 433-467 
Nota: Os valores na diagonal da tabela, em negrito, representam as variâncias extraídas, enquanto que os demais valores correspondem às variâncias compartilhadas.

Fonte: autores

\section{Validação do Modelo Teórico, Teste de Hipóteses e Coeficientes de Correlação}

Para a validação do Modelo Teórico, a partir da estimação do modelo híbrido, foram obtidas as medidas de ajuste (Tabela 5). O GFI e o AGFI não resultaram em valores satisfatórios, embora tanto o RMSEA quanto o TLI, o NFI e o CFI contemplem os valores de referência recomendados pela literatura. Tendo em vista o ineditismo do Modelo Teórico proposto, não havendo evidências empíricas anteriores que possibilitem comparações efetivas, conforme já comentado, entende-se que o modelo, mesmo que não tenha valores satisfatórios, em todas as medidas de ajuste, suscita um "amadurecimento", o qual poderá advir ou do seu aperfeiçoamento teórico ou com novos estudos empíricos, portanto, não o invalidando.

Tabela 5 - Medidas de ajuste do Modelo Teórico

\begin{tabular}{c|c|c|c|c|c|c}
\hline Modelo Teórico & GFI & AGFI & RMSEA & TLI & NFI & CFI \\
\hline Valores das medidas de ajuste & 0,836 & 0,786 & 0,080 & 0,925 & 0,906 & 0,938 \\
\hline
\end{tabular}

Fonte: autores

No que diz respeito às medidas de qualidade de ajuste do modelo é preciso que se faça uma ressalva. Considerar o modelo aceitável se, e somente se, tais medidas excederem o valor de referência não é uma regra totalmente confiável e infalível, pois os modelos não reagem igualmente bem com vários tipos de medidas de adequação, tamanhos de amostra, de estimadores ou tipos de distribuição (HU; BENTLER, 1995). Além de analisar o ajuste do modelo a partir dos pontos de corte ou dos valores de referência recomendados, preferencialmente avaliando as medidas em conjunto, e não isoladamente (HULLAND; CHOW; LAM, 1996), deve-se, considerar a sua razoabilidade, contribuição substantiva ao campo de estudos e seu significado empírico (BOLLEN, 1989; MULAIK et al., 1989).

Para testar as hipóteses estabelecidas para o Modelo Teórico, examinou-se a significância e a magnitude dos coeficientes de regressão estimados. Um coeficiente de regressão significativo indica que a relação entre duas variáveis é comprovada empiricamente (HAIR Jr. et al., 1998). Os resultados são apresentados na Tabela 6. 
Tabela 6 - Resultados do teste de hipóteses - Modelo Teórico

\begin{tabular}{c|c|c|c|c|c|c|c}
\hline Hi & $\begin{array}{c}\text { Caminhos } \\
\text { Estruturais }\end{array}$ & $\begin{array}{c}\text { Coeficientes Não } \\
\text { Padronizados (b) }\end{array}$ & Erros & $\begin{array}{c}\text { Coeficientes } \\
\text { Padronizados ( } \boldsymbol{\beta})\end{array}$ & $\boldsymbol{t}$-values & P & Resultado \\
\hline H1 & SATISF $\rightarrow$ VALOR & 1,649 & 0,177 & 1,635 & 9,314 & 0,000 & Aceita \\
\hline H2 & VALOR $\rightarrow$ REPUT & 0,248 & 0,246 & 0,503 & 1,008 & 0,313 & Rejeitada \\
\hline H3 & REPUT $\rightarrow$ CONF & 1,238 & 0,077 & 0,989 & 16,053 & 0,000 & Aceita \\
\hline H4 & CONF $\rightarrow$ VALOR $*$ & $-1,386$ & 0,310 & $-0,853$ & $-4,466$ & 0,000 & Rejeitada \\
\hline H5 & CONF $\rightarrow$ REPUT $*$ & 0,399 & 0,410 & 0,499 & 0,973 & 0,331 & Rejeitada \\
\hline H6 & CONF $\rightarrow$ RETEN & 1,487 & 0,083 & 0,926 & 17,972 & 0,000 & Aceita \\
\hline
\end{tabular}

Notas: 1) * Relações recursivas (loopings); e 2) teste de hipóteses ao nível de significância de 0,05 .

Fonte: autores

Pelos resultados, conclui-se que das seis hipóteses de pesquisa, três podem ser aceitas e três rejeitadas. As hipóteses H1 (o valor percebido pelos clientes é positivamente influenciado pela satisfação dos clientes), H3 (a confiança no provedor de serviços é positivamente influenciada pela reputação do provedor de serviços) e H6 (a retenção de clientes é positivamente influenciada pela confiança no provedor de serviços) são suportadas. Já as hipóteses $\mathbf{H 2}$ (a reputação do provedor de serviços é positivamente influenciada pelo valor percebido pelos clientes), H4 (o valor percebido pelos clientes é positivamente influenciado pela confiança no provedor de serviços) e H5 (a reputação do provedor de serviços é positivamente influenciada pela confiança no provedor de serviços) são rejeitadas.

Finalmente, foram analisados os coeficientes de determinação $\left(\mathrm{R}^{2}\right)$, calculados pelas correlações múltiplas ao quadrado de cada variável dependente, e que são apresentados na Tabela 7.

Tabela 7 - Coeficientes de determinação - Modelo Teórico

\begin{tabular}{c|c}
\hline Variáveis Dependentes & Coeficientes de Determinação $\left(\mathbf{R}^{\mathbf{2}}\right)$ \\
\hline VALOR & 0,569 \\
\hline REPUT & 0,919 \\
\hline CONF & 0,982 \\
\hline RETEN & 0,857 \\
\hline
\end{tabular}

Fonte: autores 
Os coeficientes de determinação são úteis para determinar a importância relativa de cada uma das relações causais testadas (HAIR Jr. et al., 1998), representando o efeito combinado das variáveis independentes sobre as variáveis dependentes, indicando a proporção de variância de uma variável dependente que é explicada pelas variáveis independentes. Conseqüentemente, coeficientes de determinação com valores altos significam um grande poder explicativo da equação de regressão (SANTOS, 2001).

Como o coeficiente de determinação indica a proporção de variância de uma variável dependente, que é explicada pelas variáveis independentes, tem-se os seguintes resultados: 85,70\% da variância da Retenção de Clientes é explicada por suas variáveis independentes, no caso, Confiança, Reputação do Provedor de Serviços, Valor e Satisfação de Clientes; 98,20\% da variância da Confiança é explicada pela Reputação do Provedor de Serviços, pelo Valor e pela Satisfação de Clientes; $91,90 \%$ da variância da Reputação do Provedor de Serviços é explicada pelo Valor e pela Satisfação de Clientes; e 56,90\% da variância do Valor é explicada pela Satisfação de Clientes. Tais resultados sugerem um alto poder de explicação para os construtos inseridos no modelo, exceto para a variável dependente Valor.

\section{Reespecificação do Modelo}

Conforme sugerido na literatura (MacCALLUM, 1995; KLINE, 2005), é justificável que se proceda reespecificações no modelo, pois é pouco provável que um modelo especificado em um primeiro momento se torne uma representação plausível dos dados (BAUMGARTNER; HOMBURG, 1996). Assim, a partir dos resultados obtidos na análise e validação do Modelo Teórico, migrou-se para a tentativa de evolução no modelo, observando a viabilidade teórica da reespecificação a ser implementada (BREI; LIBERALI, 2004).

Não pretendendo descaracterizar o Modelo Teórico proposto, percebeu-se relativa dificuldade na estimação dos parâmetros em relações recursivas (loopings), caso das hipóteses 4 e H5, ambas rejeitadas no teste de hipóteses descrito na seção anterior. Somando-se a isso, foi considerada a intenção de aumentar a parcimônia nas relações causais do modelo. Nesta direção, foram eliminadas as duas relações causais recursivas (H4 e H5), testando-se o Modelo Teórico Reespecificado (Figura 3), que obteve os seguintes resultados (Tabela 8).

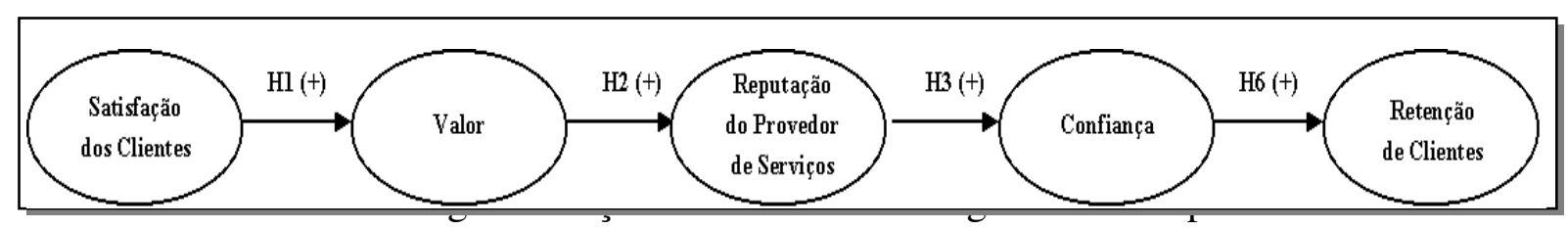


Figura 3 - Modelo Teórico Reespecificado

Fonte: autores

Tabela 8 - Medidas de ajuste do Modelo Teórico Reespecificado

\begin{tabular}{c|c|c|c|c|c|c}
\hline Modelo Teórico Reespecificado & GFI & AGFI & RMSEA & TLI & NFI & CFI \\
\hline Valores das medidas de ajuste & 0,837 & 0,786 & 0,079 & 0,926 & 0,907 & 0,939 \\
\hline
\end{tabular}

Fonte: autores

Embora tenha havido alguma melhoria nos valores, como é o caso do GFI, que passou de 0,836 para 0,837 ; do RMSEA que passou de 0,080 para 0,079 ; do TLI que passou de 0,925 para 0,926; do NFI que passou de 0,906 para 0,907; e do CFI que passou de 0,938 para 0,939; é possível dizer que tal incremento no ajuste do modelo é imperceptível.

No teste de hipóteses, percebe-se que a hipótese $\mathrm{H}_{2}$, anteriormente rejeitada, passou a ser aceita, demonstrando que as relações estabelecidas nas hipóteses $\mathrm{H}_{4}$ e $\mathrm{H}_{5}$ poderiam mesmo ser retiradas do Modelo Teórico inicial. Os resultados constam da Tabela 9.

Tabela 9 - Resultados do teste de hipóteses - Modelo Teórico Reespecificado

\begin{tabular}{|c|c|c|c|c|c|c|c|}
\hline Hi & $\begin{array}{c}\text { Caminhos } \\
\text { Estruturais }\end{array}$ & $\begin{array}{l}\text { Coeficientes Não } \\
\text { Padronizados (b) }\end{array}$ & Erros & $\begin{array}{c}\text { Coeficientes } \\
\text { Padronizados }(\beta) \\
\end{array}$ & t-values & $\mathbf{P}$ & Resultado \\
\hline $\mathrm{H} 1$ & SATISF $\rightarrow$ VALOR & 0,897 & 0,039 & 0,981 & 22,958 & 0,000 & Aceita \\
\hline $\mathbf{H 2}$ & VALOR $\rightarrow$ REPUT & 0,494 & 0,033 & 0,905 & 14,743 & 0,000 & Aceita \\
\hline $\mathrm{H} 3$ & REPUT $\rightarrow$ CONF & 1,221 & 0,077 & 0,977 & 15,875 & 0,000 & Aceita \\
\hline $\mathrm{H} 4$ & $\mathrm{CONF} \rightarrow \mathrm{VALOR} *$ & \multicolumn{6}{|c|}{ Hipótese eliminada na reespecificação do Modelo Teórico } \\
\hline H5 & $\mathrm{CONF} \rightarrow \mathrm{REPUT} *$ & \multicolumn{6}{|c|}{ Hipótese eliminada na reespecificação do Modelo Teórico } \\
\hline H6 & CONF $\rightarrow$ RETEN & 1,487 & 0,082 & 0,927 & 18,085 & 0,000 & Aceita \\
\hline
\end{tabular}

Fonte: autores

Em relação aos coeficientes de determinação (Tabela 10), a variância da Retenção de Clientes, que era explicada em $85,70 \%$ por suas variáveis independentes (Confiança, Reputação do Provedor de Serviços, Valor e Satisfação de Clientes) passou a ser explicada em $85,90 \%$, havendo uma pequena melhoria em seu poder de explicação. A variância da Confiança, que era explicada em 98,20\% pela Reputação do Provedor de Serviços, pelo Valor e pela Satisfação de Clientes, passou a ser explicada em 95,50\%, havendo uma diminuição. A variância da Reputação do Provedor de Serviços, que era explicada em 91,90\% pelo Valor e pela Satisfação de Clientes, passou a ser explicada em 82,00\%, havendo 
diminuição. E, finalmente, a variância do Valor, que era explicada em 56,90\% pela Satisfação de Clientes, passou a ser explicada em 96,30\%, havendo uma melhoria substancial.

Tabela 10 - Coeficientes de determinação - Modelo Teórico Reespecificado

\begin{tabular}{c|c}
\hline Variáveis Dependentes & Coeficientes de Determinação $\left(\mathbf{R}^{\mathbf{2}}\right)$ \\
\hline VALOR & 0,963 \\
\hline REPUT & 0,820 \\
\hline CONF & 0,955 \\
\hline RETEN & 0,859 \\
\hline
\end{tabular}

Fonte: autores

Os resultados continuam indicando um alto poder de explicação para os construtos inseridos no modelo, inclusive, possibilitando a inferência de sua melhoria global. Contudo, mantendo-se praticamente o mesmo nível de ajuste do modelo, houve melhoria na parcimônia das relações causais estabelecidas, com a confirmação da hipótese $\mathrm{H} 2$, sem descaracterizar teoricamente o modelo, "forçando um ajuste desejável", podendo-se concluir que o Modelo Teórico Reespecificado é uma evolução do Modelo Teórico inicialmente proposto.

\section{CONSIDERAÇÕES FINAIS}

Em um primeiro momento, foi proposto um Modelo Teórico que pudesse explicar a prática do marketing de relacionamento de um provedor de serviços representativo na economia brasileira e mundial, estabelecendo-se algumas relações causais entre construtos que fazem parte do contexto das trocas relacionais e que resultassem na retenção de clientes. Ao testar o Modelo Teórico, apenas três das seis hipóteses foram suportadas ( $\mathrm{H}_{1}, \mathrm{H} 3$ e H6), além do modelo não apresentar, para os valores das medidas de ajuste, valores convergentes aos parâmetros recomendados. Assim, conforme a literatura (MacCALLUM, 1995; BAUMGARTNER; HOMBURG, 1996; BREI; LIBERALI, 2004; KLINE, 2005), buscou-se, por meio da reespecificação do modelo, melhorar tanto o ajuste do modelo quanto o teste de hipóteses, sem violentar os pressupostos teóricos seguidos e os dados, de forma conveniente.

Foram eliminadas, do Modelo Teórico inicialmente proposto, duas hipóteses $\left(\mathrm{H}_{4} \mathrm{e}\right.$ H5), que apresentavam relações recurssivas (loopings). O Modelo Teórico Reespecificado não demonstrou resultados de ajuste superiores ao Modelo Teórico inicial. No entanto, este REAd I Porto Alegre - Edição 72 - N 2 - maio/agosto 2012 - p. 433-467 
modelo serviu para suportar as quatro hipóteses intrínsecas a ele. Foi confirmado, então, que o valor percebido pelos clientes é positivamente influenciado pela satisfação dos clientes (H1), que a reputação do provedor de serviços é positivamente influenciada pelo valor percebido pelos clientes (H2); que a confiança no provedor de serviços é positivamente influenciada pela reputação do provedor de serviços $(\mathbf{H 3})$, e que a retenção de clientes é positivamente influenciada pela confiança no provedor de serviços (H6).

Dessa forma, entende-se que o trabalho avança no sentido de propiciar evidências teórico-empíricas no que diz respeito ao Valor como um construto antecedente à Confiança, relação esta mediada pela Reputação no Provedor de Serviços; à relevância da Reputação no Provedor de Serviços no contexto relacional, servindo como uma referência para o mercado, influenciando positivamente a avaliação da qualidade dos serviços prestados, a satisfação e o valor percebido pelos clientes; e à constatação de que a Retenção de Clientes é diretamente influenciada pela Confiança que o cliente deposita no provedor de serviços.

É imperioso comentar que o trabalho apresenta algumas limitações. A primeira se refere ao fato da pesquisa ter sido realizada com uma abordagem do tipo corte transversal único, não permitindo verificar mudanças na percepção dos respondentes, o que poderia alterar as relações entre os construtos analisados ao longo do tempo. Além do mais, como a amostra contemplou clientes de um único provedor de serviços, localizados em apenas duas regiões do Estado do Rio Grande do Sul, a generalização dos resultados é prejudicada.

Outro aspecto a ser considerado é que o Modelo Teórico Reespecificado, embora tenha obtido medidas de ajuste levemente melhores que o Modelo Teórico inicial, resultou em um ajuste aquém do recomendado. Ainda que este modelo não seja um modelo consolidado, propondo relações inéditas, salienta-se a necessidade de um maior amadurecimento entre as relações causais propostas e do próprio modelo integrado. O Modelo Teórico Reespecificado não se configura como uma representação definitiva da prática relacional da empresa em estudo, mas sim, a melhor representação desta prática dentre os modelos analisados.

No sentido de minimizar ou eliminar tais limitações da pesquisa, é possível vislumbrar a adoção de outros procedimentos ou técnicas de pesquisa, bem como o desenvolvimento de pesquisas futuras. Como uma evolução ao presente trabalho, é sugerida a utilização de amostras probabilísticas e longitudinais, o que possibilitaria uma comparação direta com os resultados obtidos com o intuito de melhorar o ajuste do modelo.

É indicada a replicação desta pesquisa em outras condições relacionais, do tipo business-to-consumer, ao invés de business-to-business, em relacionamentos descontinuados, 
com a presença, ou não, de mecanismos regulatórios formais (contratos), ao invés de relacionamentos contínuos, como foi o caso deste trabalho, e em outros setores de serviços, como, por exemplo, varejo, serviços financeiros, dentre outros. A replicação da pesquisa em outros ambientes de serviços, e com diferentes características relacionais na díade usuárioprovedor de serviços, poderia propiciar evidências comparativas que viessem a melhorar o ajuste do modelo, confirmando-o, ou não, conforme a situação de pesquisa. Emerge, ainda, a possibilidade de uma depuração mais radical nas escalas utilizadas, reduzindo-se o número de variáveis observáveis ou indicadores, o que poderia acarretar em um melhor ajuste do modelo.

Apesar das limitações intrínsecas à pesquisa e das possibilidades inerentes ao desenvolvimento de pesquisas futuras, entende-se que, tanto a prática do marketing de relacionamento e a retenção de clientes em ambientes de serviço, quanto a utilização da Modelagem de Equações Estruturais, por seu poder de explicação estatístico e por se tratar de uma abordagem ainda pouco difundida no Brasil, conferem ao trabalho, e seus respectivos resultados, relevância teórico-empírica ou acadêmico-gerencial.

\section{REFERÊNCIAS}

ALSOP, R. J. Corporate reputation: anything but superficial - the deep but fragile nature of corporate reputation. Journal of Business Strategy, v. 25, n. 6, p. 21-29, 2004.

ANDERSON, E. W. Customer satisfaction and word-of-mouth. Working Paper, NQRC (National Quality Research Center): The University of Michigan, July 1998.

Cross-category variation in customer satisfaction and retention. Marketing Letter, v. 5, n. 1, p. 19-30, Jan. 1994.

; FORNELL, C. A customer satisfaction research prospectus. In: RUST, R. T.; OLIVER, R. L. (Eds.). Quality: new directions in theory and practice. Thousand Oaks: Sage Publications, 1994. p. 241-268.

; ___ _ LEHMANN, D. R. Perceived quality, customer satisfaction, market share, and profitability. Working Paper, NQRC (National Quality Research Center): The University of Michigan, 1992.

REAd I Porto Alegre - Edição 72 - N 2 - maio/agosto 2012 - p. 433-467 
; ___ C C C C _ _ Sweden. Journal of Marketing, v. 58, n. 3, p. 53-66, July 1994.

; MITTAL, V. Strengthening the satisfaction-profit chain. Journal of Service Research, v. 3, n. 2, p.107-120, 2000.

ANDERSON, J. C.; GERBING, D. W. Structural equation modeling in practice: a review and recommended two-step approach. Psychological Bulletin, v. 103, p. 411-423, 1988.

ANDREASSEN, T. W.; LINDESTAD, B. Customer loyalty and complex services. International Journal of Service Industry Management, v. 9, n. 1, p. 7-23, 1998.

APÉRIA, T.; BRONN, P. S.; SCHULTZ, M. A reputation analysis of the most visible companies in the Scandinavian countries. Corporate Reputation Review, v. 7, n. 3, p. 218230, 2004.

ARBUCKLE, J. L. AMOS ${ }^{\mathrm{TM}}$ user's guide. Chicago: SPSS, 2009.

AGUSTIN, C.; SINGH, J. Curvilinear effects as customer loyalty determinants in relational exchanges. Journal of Marketing Research, v. 42, n. 1, p. 96-108, Feb. 2005.

BABIN, B. J.; GRIFFIN, M. The nature of satisfaction: an updated examination and analysis. Journal of Business Research, v. 41, n. 2, p. 127-136, Feb. 1998.

BAGOZZI, R. P.; YI, Y.; PHILLIPS, L. W. Assessing construct validity in organizational research. Administrative Science Quarterly, v. 36, n. 3, p. 421-458, Sep. 1991.

BARNEY, J. B.; HANSEN, M. H. Trustworthiness as a source of competitive advantage. Strategic Management Journal, v. 15, n. 8, p. 175-190, Winter 1994.

BAUMGARTNER, H.; HOMBURG, C. Application of structural equation modeling in marketing and consumer research: a review. International Journal of Research in Marketing, v. 13, n. 2, p. 139-161, Apr. 1996.

BEARDEN, W. O.; TEEL, J. E. Selected determinants of consumer satisfaction and complaint reports. Journal of Marketing Research, v. 20, n. 1, p. 21-28, Feb. 1983. 
BERRY, L. L. Relationship marketing of services - perspectives from 1983 and 2000. Journal of Relationship Marketing, v. 1, n. 1, p. 59-77, 2002.

BITNER, M. J. Building service relationships: it's all about promises. Journal of the Academy of Marketing Science, v. 23, n. 4, p. 246-251, Fall 1995.

BLACKWELL, R. D.; MINIARD, P. W.; ENGEL, J. F. Consumer behavior. $4^{\text {th }}$ edition. Hartcourt, 2001.

BOLLEN, K. A. Structural equations with latent variables. Wiley Series in Probability and Mathematical Statistics. New York: John Wiley \& Sons, 1989.

BOLTON, R. N. A dynamic model of the duration of the customer's relationship with continuous service provider: the role of satisfaction.Marketing Science, v. 17, n. 1, p. 45-65, 1998.

BOULDING, W.; KALRA, A.; STAELIN, R.; ZEITHAML, V. A. A dynamic process model of service quality: from expectations to behavioral intentions. Journal of Marketing Research, v. 30, n. 1, p. 7-27, Feb. 1993.

BREI, V. A.; LIBERALI, G. O uso de modelagem em equações estruturais na área de marketing no Brasil. In: I EMA, 2004. Porto Alegre. Anais...Porto Alegre: ANPAD, 2004.

BYRNE, B. M. Structural equation modeling with AMOS: basic concepts, applications, and programming. $2^{\text {nd }}$ edition. New York: Taylor \& Francis Group, 2009.

CANNON, J. P.; PERREAULT Jr., W. D. Buyer-seller relationships in business markets. Journal of Marketing Research, v. 36, n. 4, p. 439-460, Nov. 1999.

CARMELI, A. The link between organizational elements, perceived external prestige and performance. Corporate Reputation Review, v. 6, n. 4, p. 314-331, 2004.

CHURCHILL Jr., G. A. A paradigm for developing better measures of marketing constructs. Journal of Marketing Research, v. 16, n. 1, p. 64-73, Feb. 1979.

Marketing research:methodologicalfoundations. $6^{\text {th }}$ edition. Orlando:DrydenPress, 1995.

REAd I Porto Alegre - Edição 72 - N 2 - maio/agosto 2012 - p. 433-467 

ambiente de serviços

CLAYCOMB, C.; MARTIN, C. L. Building customer relationships: an inventory of service providers' objectives and practices. Marketing Intelligence \& Planning, v. 19, n. 6/7, p. 385-399, 2001.

COULTER, K. S.; COULTER, R. A. Determinants of trust in a service provider: the moderating role of length of relationship. Journal of Services Marketing, v. 16, n. 1, p. 35-50, 2002.

CRONIN Jr., J. J.; BRADY, M. K.; HULT, G. T. M. Assessing the effects of quality, value, and customer satisfaction on consumer behavioral intentions in service environments. Journal of Retailing, v. 76, n. 2, p. 193-218, Summer 2000.

CUDECK, R. Analysis of correlation matrices using covariance structure models. Psychological Bulletin, v. 105, p. 317-327, 1989.

DEUTSCH, M. Cooperation and trust: some theoretical notes. In: JONES, M. R. (Ed.), Nebraska Symposium on Motivation. Lincoln, Nebraska: University of Nebraska Press, 1962.p. 275-319.

DIAMANTOPOULOS, A.; WINKLHOFER, H. M. Index construction with formative indicators: analternativetoscaledevelopment.JournalofMarketing Research,v.38, n.2,p. 269-277, 2001.

DILLON, W. R.; MADDEN, T. J.; FIRTLE, N. H. Marketing research in a marketing environment. St. Louis: Times Mirror, 1994.

DONEY, P.; CANNON, J. P. An examination of the nature of trust in buyer-seller relationships. Journal of Marketing, v. 61, n. 2, p. 35-51, Apr. 1997.

DUNN,S.C.;SEAKER, R. F.; WALLER, M. A. Latent variables in business logistic research: scale development and validation. Journal of Business Logistics, v. 15, n. 2, p. 145-172, 1994.

FINN, A. Aremarketers deluding themselves with reported Coefficient Alphas? Paper submitted for possible presentation at EMAC 2001. Rethinking Marketing Research Track, Nov. 2000.

FITZSIMMONS, J. A.; FITZSIMMONS, M. J. Administração de serviços: operações, estratégia e tecnologia da informação. 4. ed. Porto Alegre: Bookman, 2005. 
FONTENOT, R. J. et al. Effect of buyer-seller relationship structure on firm performance. In: AMA - American Marketing Association - Winter Conference, 1998. Austin, Texas. Proceedings...Austin: AMA - American Marketing Association, 1998.

FORNELL, C. Productivity, quality, and customer satisfaction as strategic success indicators at firm and national level. Advances in Strategic Management, v. 11A, p. 217-229, 1995.

; LARCKER, D. F. Evaluating structural equation models with unobservable variables and measurement error: algebra and statistics. Journal of Marketing, v. 18, n. 1, p. 39-59, Feb. 1981.

; RYAN, M.; WESTBROOK, R. Customer satisfaction: the key to customer satisfaction. Mobius, v. 9, n. 3, p. 14-18, 1990.

; WERNERFELT, B. Defensive marketing strategy by customer complaint management: a theoretical analysis. Journal of Marketing Research, v. 24, n. 4, p. 337-346, Nov. 1987.

GANESAN, S. Determinants of long-term orientation in buyer-seller relationships. Journal of Marketing, v. 58, n. 2, p. 1-19, Apr. 1994.

GANESH, J.; ARNOLD, M. J.; REYNOLDS, K. Understanding the customer base of service providers: an examination of the differences between switchers and stayers. Journal of Marketing, v. 64, n. 3, p. 65-87, July 2000.

GARBARINO, E.; JOHNSON, M. S. The different roles of satisfaction, trust, and commitment in customer relationships. Journal of Marketing, v. 63, n. 2, p. 70-87, Apr. 1999.

GARVER, M. S.; MENTZER, J. T. Logistics research methods: employing structural equation modeling to test for construct validity. Journal of Business Logistics, v. 20, n. 1, p. 33-57, 1999.

GARVIN, D. A. Competing on the eight dimensions of quality. Harvard Business Review, v. 65, n. 6, p. 101-110, Nov.-Dec. 1987.

GERBING, D. W.; ANDERSON, J. C. An updated paradigm for scale development incorporating unidimensionality and its assessment. Journal of Marketing Research, v. 25, n. 2, p. 186-192, May 1988. 

ambiente de serviços

GRÖNROOS, C. From marketing mix to relationship marketing: towards a paradigm shift in marketing. Management Decision, v. 32, n. 4, p. 4-20, 1994.

HAIR Jr., J.F.etal.Multivariatedataanalysis. $5^{\text {th }}$ edition.Upper Saddle River:Prentice Hall, 1998.

; BUSH, R. P.; ORTINAU, D. J. Marketing research: a practical approach for the new millennium. New York: Irwin/McGraw-Hill, 2000.

HALLOWELL, R. The relationships of customer satisfaction, customer loyalty, and profitability: an empirical study. International Journal of Service Industry Management, v. 7, n. 4, p. 27-42, 1996.

HAWES, J. M.; MAST, K. E.; SWAN, J. E. Trust earning perceptions of sellers and buyers. The Journal of Personal Selling \& Sales Management, v. 9, n. 1, p. 1-8, Spring 1989.

HAWKINS, D. I.; BEST, R. J.; CONEY, K. A. Consumer behavior: implications for marketing strategy. $6^{\text {th }}$ edition. Chicago: Irwin, 1995.

HENNIG-THURAU, T.; GWINNER, K. P.; GREMLER, D. D. Understanding relationship marketing outcomes: an integration of relational benefits and relationship quality. Journal of Service Research, v. 4, n. 3, p. 230-247, Feb. 2002.

HESKETT, J. L. et al. Putting the service-profit chain to work. Harvard Business Review Business Classics: Fifteen Key Concepts for Managerial Success, p.110-120, 1994.

HEWETT, K.; MONEY, R. B.; SHARMA, S. An exploration of the moderating role of buyer corporate culture in industrial buyer-seller relationships. Journal of the Academy of Marketing Science, v. 30, n. 3, p. 229-239, Summer 2002.

HOLBROOK, M. B. Consumer value: a framework for analysis and research. New York: Routledge, 1999.

HOWARD,J.A.;SHETH,J.N.The theory ofbuyerbehavior.New York:John Wiley \& Sons, 1969.

HOYLE, R. H. The structural equation modeling approach: basic concepts and fundamental issues. In: HOYLE, R. H. (Ed.). Structural equation modeling: concepts, issues, and applications. Thousand Oaks: Sage Publications, 1995. cap. 1, p. 1-15. 
; PANTER; A. T. Writing about structural equation modeling. In: HOYLE, R. H. (Ed.). Structural equation modeling: concepts, issues, and applications. Thousand Oaks: Sage Publications, 1995. cap. 9, p. 158-176.

HU, L.; BENTLER; P. M. Evaluating model fit. In: HOYLE, R. H. (Ed.). Structural equation modeling: concepts, issues, and applications. Thousand Oaks: Sage Publications, 1995. cap. 5, p. 76-99.

HULLAND, J.; CHOW, Y. H.; LAM, S. Use of causal models in marketing research: a review. International Journal of Research in Marketing, v. 13, n. 2, p. 181-197, 1996.

JARVIS, C. B.; MACKENZIE, S. B.; PODSAKOFF, P. M. A critical review of construct indicators and measurement model misspecification in marketing and consumer research. Journal of Consumer Research, v. 30, n. 2, p. 199-218, Sep. 2003.

JOHNSON, M. D.; FORNELL, C. A framework for comparing customer satisfaction across individuals and product categories. JournalofEconomicPsychology, v.12,n.2, p.267-286, 1991.

JOHNSON, R. A.; WICHERN, D. W. Applied multivariate statistical analysis. $3^{\text {rd }}$ edition. International Edition: Prentice Hall, 1992.

JURAN, J. M.; GODFREY, A. B. Juran's quality handbook. $5^{\text {th }}$ edition. New York: McGraw-Hill, 1999.

KINNEAR, T. C.; TAYLOR, J. R. Marketing research: an applied approach. $5^{\text {th }}$ edition. New York: McGraw-Hill, 1996.

KLINE, R. B. Principles and practice of structural equation modeling. $2^{\text {nd }}$ edition. New York: The Guilford Press, 2005.

KOTLER, P. Administração de marketing. 10. ed. São Paulo: Prentice Hall, 2000.

MAATHUIS, O.; RODENBURG, J.; SIKKEL, D. Credibility, emotion or reason? Corporate Reputation Review, v. 6, n. 4, p. 333-345, 2004. 

ambiente de serviços

MacCALLUM, R. C. Model specification: procedures, strategies and related issues. In: HOYLE, R. H. (Ed.). Structural equation modeling: concepts, issues, and applications. Thousand Oaks: Sage Publications, 1995. cap. 2, p. 16-36.

MALHOTRA, N. K. Pesquisa de marketing. 4. ed. Porto Alegre: Bookman, 2006.

MARSH, H. W.; GRAYSSON, D. Latent variable models of multitrait-multimethod data. In: HOYLE, R. H. (Ed.). Structural equation modeling: concepts, issues, and applications. Thousand Oaks: Sage Publications, 1995. cap. 10, p. 177-198.

MAYER, R. C.; DAVIS, J. H.; SCHOORMAN, F. D. An integrative model of organizational trust. Academy of Management Review, v. 20, n. 3, p. 709-734, 1995.

McALLISTER, D. J. Affect and cognition-based trust as foundations for interpersonal cooperation in organizations. Academy of Management Journal, v. 38, n. 1, p. 24-59, 1995.

MILAN, G. S. A retenção de clientes como prática do marketing de relacionamento. In: MILAN, G. S.; BRANCHI, N. V. L. (org.). Administração mercadológica: teoria e pesquisas. Caxias do Sul: EDUCS, 2004. cap. 8, p. 177-195.

A prática do marketing de relacionamento e a retenção de clientes: um estudo aplicado em um ambiente de serviços. 2006. Tese (Doutorado). Escola de Engenharia de Produção, UFRGS, Porto Alegre.

MITTAL, B.; LASSAR, W. M. Why customers switch? The dynamics of satisfaction versus loyalty. Journal of Services Marketing, v. 12, n. 3, p. 177-194, 1998.

MORGAN, R. M.; HUNT, S. D. The commitment-trust theory of relationship marketing. Journal of Marketing, v. 58, n. 3, p. 20-38, July 1994.

MULAIK, S. A. et al. Evaluation of goodness-of-fit indices for structural equation models. Psychological Bulletin, v. 105, n. 3, p. 430-445, 1989.

NOOTEBOOM, B.; BERGER, H.; NOORDERHAVEN, N. G. Effects of trust and governance on relational risk. Academy of Management Journal, v. 40, n. 2, p. 308-338, 1997. 
NUNNALLY, J. C.; BERNSTEIN, I. H. Psychometric theory. $3^{\text {rd }}$ edition. New York: McGraw-Hill, 1994.

OLIVER, R. L. A cognitive model of the antecedents and consequences of satisfaction decisions. Journal of Marketing Research, v. 17, n. 4, p. 460-469, Nov. 1980.

Measurement and evaluation of satisfaction process in retail setting. Journal of Retailing, v. 57, n. 3, p. 25-48, Fall 1981.

A conceptual model of service quality and service satisfaction: compatible goals, different concepts In: Advances in Services Marketing and Management. Greenwich: JAI Press, v. 2, p. 65-85, 1993.

Whence consumer loyalty? Journal of Marketing, v. 63, n. 4, p. 33-44, Oct. 1999a.

Value as excellence in the consumption experience. In: HOLBROOK, M. B. (Ed.). Consumer value: a framework for analysis and research.New York: Routledge, 1999b.p.43-62.

Satisfaction: a behavioral perspective on the consumer. $2^{\text {nd }}$ edition. New York: Irwin/McGraw-Hill, 2010.

PERIN, M. G. A relação entre orientação para mercado, aprendizagem organizacional $e$ performance. 2001. Tese (Doutorado). Escola de Administração, Programa de Pós-Graduação em Administração, UFRGS, Porto Alegre.

et al. As relações entre confiança, valor e lealdade: um estudo intersetorial. In: XXVIII ENANPAD, 2004. Curitiba. Anais...Curitiba: ANPAD, 2004.

PILLAI, K. G.; SHARMA, A. Mature relationships: why does relational orientation turn into transaction orientation? Industrial Marketing Management, v. 32, p. 643-651, 2003.

REICHHELD, F. F. Loyalty-based management. Harvard Business Review, v. 71, n. 2, p. 64-73, Mar.-Apr. 1993.

The loyalty effect: the hidden force behind growth, profits, and lasting value. Boston: Harvard Business School Press, 1996.

REAd I Porto Alegre - Edição 72 - N 2 - maio/agosto 2012 - p. 433-467 

ambiente de serviços

; MARKEY Jr., R. G.; HOPTON, C. The loyalty effect: the relationship between loyalty and profits. European Business Journal, v. 12, n. 3, p. 134-139, 2000.

; SASSER Jr., W. E. Zero defections: quality comes to service. Harvard Business Review, v. 68, n. 5, p. 105-111, Sep.-Oct. 1990.

ROUSSEAU, D. M. et al. Not so different after all: a cross-discipline view of trust. Academy of Management Review, v. 23, n. 3, p. 393-404, 1998.

ROTTER, J. B. A new scale for the measurement of interpersonal trust. Journal of Personality, v. 35, p. 651-665, 1967.

RUST, R. T.; ZAHORIK, A. J. Customer satisfaction, customer retention, and market share. Journal of Retailing, v. 69, n. 2, p. 193-215, 1993.

; ZEITHAML, V. A.; LEMON, K. N. Driving customer equity: how customer lifetime value is reshaping corporate strategy. New York: The Free Press, 2000.

SANTOS, C. P. Impacto do gerenciamento de reclamações na confiança e lealdade do consumidor no contexto de trocas relacionais de serviços: construção e teste de um modelo teórico. 2001. Tese (Doutorado). Escola de Administração, UFRGS, Porto Alegre.

SHARMA, A. The metrics of relationships: measuring satisfaction, loyalty and profitability of relational customers. Journal of Relationship Marketing, v. 6, n. 2, p. 33-50, 2007.

; PILLAI, K. G. The impact of transactional and relationship strategies in business market: an agenda for inquiry. Industrial Marketing Management, v. 32, p. 623-626, 2003.

SHEPPARD, B. H.; SHERMAN, D. M. The grammars of trust: a model and general implications. Academy of Management Review, v. 23, n. 3, p. 422-437, 1998.

SHMATIKOV, V.; TALCOTT, C. Reputation-based trust management. Journal of Computer Security, v. 13, n. 1, p. 167-190, 2005.

SINHA, I.; DeSARBO, W. S. An integrated approach toward the spatial modeling of perceived customer value. Journal of Marketing Research, v. 35, n. 2, p. 236-249, May 1998. 
SIRDESHMUKH, D.; SINGH, J.; SABOL, B. Consumer trust, value, and loyalty in relational exchanges. Journal of Marketing, v. 66, n. 1, p. 15-37, Jan. 2002.

SMITH, K. G.; CARROL, S.; ASHFORD, S. J. Intra and interorganizational cooperation: toward a research agenda. Academy of Management Review, v. 38, p. 7-23, 1995.

STERN, B.; ZINKHAN, G. M.; JAJU, A. Marketing images: construct definition, measurement issue, and theory development. Marketing Theory, v. 1, n. 2, p. 201-224, 2001.

STORBACKA, K.; STRANDVIK, T.; GRÖNROOS, C. Managing customer relationship for profit: the dynamics of relationship quality. International Journal of Service Industry Management, v. 5, n. 5, p. 21-38, 1994.

SVENSSON, G.Extending trustand mutual trustinbusiness relationshipstowards a synchronized trust chain in marketing channels. Management Decision, v. 39, n. 5/6, p. 431-440, 2001.

TSE, D. K.; WILTON, P. C. Models of consumer satisfaction formation: an extension. Journal of Marketing Research, v. 25, n. 2, p. 204-212, May 1988.

VAVRA, T. G. Selling after the sale: the advantages of aftermarketing. Supervision, v. 55, n. 10, p. 9-12, Oct. 1994.

; PRUDEN, D. R. Using aftermarketing to maintain a customer base. Discount Merchandiser, v. 35, n. 5, p. 86-88, May 1995.

WEBLEY, S. Risk, reputation and trust. Journal of Communication Management, v. 8, n. 1, p. 9-12, Aug. 2003.

WICKS, A. C.; BERMAN, S. L.; JONES, T. M. The structure of optimal trust: moral and strategic implications. Academy of Management Review, v. 24, n. 1, p. 99-116, 1999.

WILCOX, J. B.; HOWELL, R. D.; BREIVIK, E. Questions about formative measurement. Journal of Business Research, v. 61, n. 2, p. 219-228, 2008.

WOODALL, T. Conceptualizing value for the customer: an attributional, structural and dispositional analysis. Academy Marketing of Science Review, n. 12, p. 1-44, 2003.

REAd I Porto Alegre - Edição 72 - N 2 - maio/agosto 2012 - p. 433-467 

ambiente de serviços

ZAND, D. E. Trust and managerial problem solving. Administrative Science Quarterly, v. 117, n. 2, p. 229-239, 1972.

ZEITHAML, V. A. Consumer perceptions of price, quality and value: a means-end model of synthesis of evidence. Journal of Marketing, v. 52, n. 3, p. 2-22, July 1988.

; BERRY, Leonard L.; PARASURAMAN, A. The behavioral consequences of service quality. Journal of Marketing, v. 60, n. 2, p. 31-46, Apr. 1996. 